\title{
Chapter 16 \\ Integrating Earth Observation Systems and International Environmental Regimes
}

\author{
Olav Schram Stokke and Oran R. Young
}

\subsection{Introduction}

How can we integrate Earth observation systems and international environmental regimes to enhance the role of satellite observations in solving a variety of large-scale environmental problems? ${ }^{1}$ As the capacity of satellite Earth observation to address environmental issues has grown, needs have arisen for enhanced coordination among major players active in this field. We noted in Chap. 1 that particularly important developments in this regard include the growing capacity of satellite observations to (i) provide crucial information on progress in meeting the objectives of issue-specific governance systems (e.g., rates of sea level rise or ocean acidification in the case of the climate change regime or rates of land degradation in the case of the regime to combat desertification); (ii) assist efforts to prevent or mitigate environmental disasters, through measures such as ice warning systems for maritime shipping, flash-flood alerts, or growth mapping of major crops such as rice, maize and soybeans; and (iii) verify compliance with regulatory arrangements

\footnotetext{
${ }^{1}$ International regimes are institutional arrangements created by states to address issues such as international trade, global warming, or fisheries management; see Chap. 1.
}

\author{
O.S. Stokke ( $\square)$ \\ Department of Political Science, University of Oslo, Blindern, PB 1097 \\ 0317 Oslo, Norway \\ e-mail: o.s.stokke@stv.uio.no \\ O.S. Stokke \\ The Fridtjof Nansen Institute, Lysaker, Norway \\ O.R. Young \\ Bren School of Environmental Science and Management, \\ University of California, Santa Barbara, CA 93106-5131, USA \\ e-mail: oran.young@gmail.com \\ (C) The Author(s) 2017


on the part of individual regime members or actors subject to the rules of various regimes.

This chapter explores in detail the question of whether these capabilities have progressed to the point where there is a compelling case to create an integrated environmental Earth observation regime complex and for establishing rules and procedures to guide interactions between providers of satellite observations and users responsible for implementing a range of international environmental agreements. To this end, we analyze organizational matters to be considered for strengthening connections between existing institutions and explore a number of normative issues associated with the development of such arrangements. We conclude with a discussion of next steps regarding the establishment of an international environmental Earth observation regime or a more coherent regime complex.

\subsection{Why Focus on Institutional Complexes?}

Alongside the proliferation of institutional arrangements in global governance and their rising density and scope, scholars have deepened our understanding of how separate institutional arrangements interact, overlap, complement, or interfere with each other in a variety of ways (e.g., Young 1996; Young 2002; Oberthür and Gehring 2006; Oberthür and Stokke 2011; Orsini et al. 2013). Frequently, governance of a particular issue area is best understood as the result of the interplay of several relevant institutions, with individual institutions affecting the contents, operations, or consequences of other institutions, whether at the same or at different levels of governance. Here, we explain why interplay within larger complexes of institutions is important in thinking about the role of Earth observation systems in addressing large-scale environmental problems.

Studying institutional complexes entails taking an aggregate view of institutional interplay. Terminology differs but considerable agreement exists regarding the conceptual core and empirical significance of this phenomenon. Among the terms in use are "clusters" (Young 1996; Oberthür and Gehring 2006), "governance architectures" (Biermann et al. 2009), "regime complexes" (Raustila and Victor 2004), and "institutional complexes" (Oberthür and Stokke 2011). The conceptual core is clear. Interplay involves interactions among institutions that are distinct in terms of membership and decision making, yet deal with the same activity, or aspects of the same activity, usually in a non-hierarchical manner. This formulation is compatible with Raustiala and Victor's often cited definition of a regime complex as a set of "partially overlapping and non-hierarchical institutions governing a particular issue-area" (Raustila and Victor 2004), but it does not preclude normative hierarchy. Although international organizations and treaties are not usually vertically ordered, elements of formal or actual subordination nevertheless may exist (Stokke and Oberthür 2011).

Among the advantages of taking an aggregate view of institutional interplay is that it directs attention to the distinctive capacities of each institution involved and 
to the ways in which several institutions may complement one another in the overall governance of an issue area. In international environmental governance, the institution best placed to generate scientific knowledge about the effects of various management programs is often different from the institution with competence to establish such programs or enforce their regulations. To illustrate, the distinctive qualities that provide the International Council for the Exploration of the Sea (ICES) with a central role in the provision of advice on North-East Atlantic fisheries are its membership, comprising the national marine science organizations of most littoral states, and its procedures developed over a period of nearly a century for insulating the advisory function from political pressure without ceding relevance to decision making (Schwach 2000). In contrast, actual regulation typically rests with narrower international bodies whose scope of membership is defined by the relationship of the stocks in question to the economic zones or high seas areas in the region (Stokke 2015). Effective compliance control may require yet another institution, because the membership of all major port states in the region covered by the North-East Atlantic Fisheries Commission (NEAFC) equips this body particularly well for orchestrating the cross-checking of fisher reports with delivery reports, port inspections, and data derived from its satellite-based Vessel Monitoring System, allowing for the integration of real-time tracking of all vessels flagged by member states (Stokke 2014). Each of the institutions involved in this institutional complex retains its operational autonomy, yet their interaction is managed in ways that enhance their combined contributions to overall fisheries governance.

Such retention of operational autonomy without foregoing the realization of gains from coordination makes the institutional complex approach especially relevant for cost-intensive and strategically sensitive activities such as satellite Earth observation. In the remainder of this chapter, we unpack this observation and explore its implications for the development of Earth observation systems to contribute to solving environmental problems.

\subsection{The Earth Observation Environmental Regime Complex}

Satellites are placed in orbit for a variety of purposes other than Earth observation, such as broadcasting or navigational guidance. Among those satellites dedicated to remote sensing, a majority are equipped primarily to tackle concerns other than environmental problem solving, including national defense and weather forecasting (Adriaensen et al. 2015). Thus, environmental agencies that aspire to tailor the planning and operation of space missions and associated data management to their specific needs must compete with numerous other stakeholders, often with closer and more longstanding relationships to those producing and distributing Earth observation data. This section outlines the Earth observation activities that are 
relevant to environmental problem solving and considers the complex of institutions that govern them.

\subsubsection{Scope of Activities in Focus}

It is helpful to divide the chain of activities that connect mission planning and environmental problem solving into three segments: acquisition of data, management of data, and use of Earth observation data for information, assistance, and compliance purposes by those responsible for implementing environmental regimes.

The acquisition of satellite Earth observation data involves a range of closely linked operations including requirement definition, sensor specification and instrumentation packaging, spacecraft launch and flight operations, and data reception (Bailey et al. 2001). Due to the complexity and costs involved, a few leading space agencies, those of the USA, (then) USSR and Japan as well as the European Space Agency (ESA), traditionally handled these operations. Since the late 1980s, however, numerous other nations, especially China and India, have developed state-of-the-art satellite imaging capacity (Morel 2013). According to a recent count, as many as 34 governments have participated in the planning, launching, and operation of some 200 civilian satellites with global land cover observing capacity, roughly half of which were still operational in Belward and Skøien (2015). Commercial Earth observation programs, such as the SPOT satellite system initiated by the French space agency Centre National d'Études Spatiales (CNES) in the 1970s, now supply very high resolution imagery to military as well civilian customers (Morel 2013). ${ }^{2}$ In addition, private firms have entered this area of activity, as imaging devices with spatial resolution as fine as $3-5 \mathrm{~m}$ have been placed on small and relatively low-cost satellites operated by major companies such as Google or Digital Globe or smaller ones like Planet Labs or Skybox (Belward and Skøien 2015). ${ }^{3}$ As a result, a large number of governmental and private actors now engage in the acquisition of Earth observation data potentially relevant to environmental problem solving.

Management of satellite Earth observation data is about distribution and archiving of the received data, often involving further processing to enhance its

\footnotetext{
${ }^{2}$ Here we apply the terminology proposed by Belward and Skøien (2015): very high resolution is less than $5 \mathrm{~m}$; high resolution is 5-9 m; medium resolution is $10-39 \mathrm{~m}$; moderate resolution is 40 $249 \mathrm{~m}$; while low resolution means $250 \mathrm{~m}-1.5 \mathrm{~km}$.

${ }^{3}$ Google acquired Skybox Imaging (from 2016 named Terra Bella) in 2014 as part of the company's efforts to provide real-time images; see OECD (2014).
} 
usefulness for particular purposes (Bailey et al. 2001). The Earth observation data providers certainly engage in these activities. But so do national and international governmental organizations closer to the end users, such as the Global Data Processing and Forecasting System (GDPFS) of the World Meteorological Organization's (WMO) World Weather Watch (WWW) programme (Dillow 2012).

Use of satellite Earth observation data for environmental problem solving, as Part I-IV of this book elaborate, involves a wide range of states and organizations for whom remote-sensing data complement other sources of information that prove helpful when conducting their respective tasks. To illustrate such complementarity, consider how satellite Earth observation data enhance the value of other pieces of information in furthering compliance with international vessel-source pollution rules in the Baltic Sea. Such compliance efforts benefit from the membership of all coastal states in the Paris MOU involving regional port authorities, and in the regional-seas regime for the area centered on the Helsinki Commission (Helcom). Member states conduct some 4000 surveillance flights every year, sometimes integrated through a Coordinated Extended Pollution Control Operation (Tahvonen 2010). In 2011, this coordinated operation involved aircraft and patrol vessels from five regional states as well as satellite surveillance provided by the CleanSeaNet Service under the EU-based European Maritime Safety Agency (EMSA). Since vessels over 300 gross tons engaged in international voyages are obliged under International Maritime Organization (IMO) rules to be equipped with Automatic Identification System (AIS) transponders, backtracking of vessels located near an oil spill can, in conjunction with a regional oil-drift forecast model endorsed by the scientific branch of the regional regime, help identify one or more likely culprits for subsequent port-state inspection (Tahvonen 2010). Thus, Earth observation data blend in with other types of information, helping to narrow the scope of those suspected of rule violation and allowing more efficient use of the port-state control mechanism (Stokke 2014). In remote-sensing terms, the user interprets the processed data conveyed in the satellite images in light of inputs from other sources, yielding "analyzed information" (Smith and Doldirina 2008) in support of environmental problem solving.

Agencies tasked with implementing the provisions of environmental regimes are newcomers among the users of satellite Earth observation data, compared to users of data located in meteorological services or national security agencies. Among the premises of this book is the proposition that there is considerable room for improvement with respect to environmental agency awareness about recent advances in satellite Earth observation technologies and the opportunities they provide for more effective detection and monitoring of environmental problems or for supporting response action or compliance mechanisms. As the next section argues, the converse is also true; the coordinating institutions set up largely by providers and managers of Earth observation data do not provide sufficient exposure to the practices and needs of environmental governance. 


\subsubsection{Boundaries of the Earth Observation Environmental Regime Complex}

The many institutions that co-govern satellite Earth observation activities derive partly from international space law centered on a small number of United Nations (UN) treaties and regional collaboration agreements adopted in the early decades of space exploration, and partly from a wide array of soft-law instruments aiming to support mutually beneficial coordination. With the rising commercialization of space, the more recent of these coordination mechanisms typically take the form of partnerships, involving national space agencies and international organizations, as well as industry associations. Prominent among those partnerships is the Group on Earth Observations (GEO), set up in 2005 to enhance the compatibility of existing observing and processing systems that would, importantly, continue to operate under their own mandates, hence the term Global Earth Observation System of Systems (GEOSS; see Part III).

The subset of space law that is relevant to Earth observation activities deals primarily with acquisition of data. The 1967 Outer Space Treaty, for example, makes clear, consistent with its broader "open-skies" principle, that satellite Earth observation is a legitimate activity that does not require consent from states or private actors observed; Article IX adds only that states are to inform others about activities that might affect their use of space. The 1972 Liability Convention makes states liable for damage caused by space objects launched from their territory, including those launched by private entities. Recently, the Permanent Court of Arbitration proposed more elaborate procedures for handling liability complaints relating to space activities (Weeden and Chow 2012). Crucial to the implementation of these various rules for coping with unintended impacts and space congestion, increasingly challenging with the deregulation and privatization of space activities during the past two decades, is the work of the International Telecommunications Union (ITU), a specialized UN agency that collaborates with national space agencies to assign satellite orbits and radio frequencies (OECD 2014; Viikari 2007).

Globally applicable provisions exist also for Earth observation data management, especially those set forth in the UN Principles Relating to Remote Sensing of Earth from Outer Space, adopted in 1986. Although that instrument is sometimes referred to as the normative centerpiece for satellite Earth observation activities (e.g., Kuriyama 2005; Smith and Doldirina 2008), it is only a non-binding resolution and its contents are not precise enough to serve as meaningful legal commitments. Nevertheless, the general thrust of the Principles is clearly favorable to those who wish to align Earth observation data provision and management to the needs of environmental problem solving. It starts out by defining remote sensing as "sensing of the Earth's surface from space ... for the purpose of improving natural resources management, land use and the protection of the environment" (Principle I), adding that such activities are to be "carried out for the benefit and in the interest of all countries" (Principle II). Hortatory language and qualifications appear as soon as norms become specific to actual management of Earth observation data. States 
are "encouraged to provide for establishment and operation of data collecting and storage stations and processing and interpretation facilities ... wherever feasible" (Principle VI), rendering Earth observation data accessible in a non-discriminatory manner and at reasonable cost (Principle XII). The most prominent soft-law norms on Earth observation data management guide states toward open-access practices but, as Smith and Doldorina (2008) point out, they are silent on the role of private companies that are steadily becoming more important in space affairs.

Actual practices regarding Earth observation data management have varied considerably among states and organizations depending on purpose and fineness of resolution. The meteorological and the oceanographic communities opted for open and free access in the 1990s (Harris and Baumann 2015); this policy was also reflected in the International Charter on Space and Major Disasters, made operational by the major space agencies in 2000 and now providing data and imaging access even to non-parties during a crisis situation. ${ }^{4}$ In other domains, data at medium resolution or finer have traditionally come at a cost (Belward and Skøien 2015). Still, the current trend among public data providers is toward free-and-open access. While cost-retrieval policies made US Landsat data subject to payment during the 1980s and 1990s, even by domestic public agencies, a gradual de-commercialization peaked in the 2008 decision to make all Landsat data available to all at no cost (Sawyer and Vries 2012). From 2009, China-Brazil Earth Resources Satellite (CBERS) program data can be downloaded free of charge by all African countries (OECD 2012); more recent policies also include Latin America. ${ }^{5}$ A similar movement is evident in the ESA Data Policy, which used to differentiate between research and commercial uses, charging for the latter (Harris and Browning 2003), but no longer does (ESA 2012). Consistent with this trend, the European Commission's Copernicus Data Policy from 2013 provides that non-sensitive data from this program are available on a "free, full and open basis" (EU 2013). ${ }^{6}$ Even commercial ventures are adapting their pricing policies: medium resolution SPOT satellite data more than 5 years old are now available free of charge to non-commercial users (Selding 2014).

This move toward more open access to publicly acquired data has been fuelled by a combination of declining prices on satellite imaging, rising concern among legislators that they are "paying twice" for Earth observation data, and growing appreciation that wide availability of such data can empower individuals, civil society, and business and stimulate the economy (Sawyer and Vries 2012). Earth observation data are included among the high-value areas in the Open Data Charter

\footnotetext{
${ }^{4}$ The Charter has been activated more than 500 times since 2000; details at www.disasterscharter. org (accessed 30 August 2016).

${ }^{5}$ Statement by China's State Administration of Science, Technology and Industry for National Defence on the occasion of the fourth joint Chinese-Brazilian Earth observation satellite being put into operation, cited in New China, 14 August 2015, http://news.xinhuanet.com/english/2015-07/ 14/c_134412054.htm (visited 4 August 2016).

${ }^{6}$ See especially Article 3 (open dissemination principles) and Articles 11-16 (on conflicting rights and sensitivity).
} 
adopted by the Group of Eight Industrialized Nations (G8), with its openness-by-default principle and its complaint that states "do not always share these data in ways that are easily discoverable, useable, or understandable to the public". 7 On this cue, as the primary international private-public partnership for improving coordination along the Earth observation chain of activities, GEO has agreed to "promote and encourage" data management principles close to the open-access end of the continuum of existing practices. Specifically, GEOSS partners and others should strive to make their Earth observation data and metadata discoverable through catalogues and search engines; accessible via online services; usable through encodings widely accepted among user communities, quality control, and comprehensive documentation of access and use conditions as well as data provenance; preserved for future use; and curated by means of correction, update, and necessary reprocessing (GEO 2015a). ${ }^{8}$ Limitations on the actual usability of available data for environmental problem solving, and how to overcome them, are the subject of the next section.

\subsection{Integrating the Earth Observation Environmental Regime Complex}

In Chap. 1, we offered a taxonomy of ways in which satellite Earth observations can promote national or international efforts to solve environmental problems. In conjunction with other types of data, satellite Earth observations can help to inform decision-makers about the severity of environmental problems by identifying undesirable conditions, monitoring their development, and assessing the adequacy of efforts to combat the problems. Satellite Earth observations can also be vital for provision of assistance to those exposed to environmental risks or disasters, like search and rescue operations or early warning systems for floods and tsunamis. In addition, satellite observations play crucial roles in certain systems for verifying compliance with international environmental commitments, as illustrated in the Helcom oil pollution case. This section identifies some important initiatives intended to strengthen each of these functions and comments on institutional adaptations that might enhance them.

\footnotetext{
${ }^{7}$ See Preamble and Principle 1 of the G8 Open Data Charter, available at https://www.gov.uk/ government/uploads/system/uploads/attachment_data/file/207772/Open_Data_Charter.pdf (accessed 2 August 2016). The G8 refers to a group of highly industrialized countries that meet annually on important economic or other issues, comprising Canada, France, Germany, Italy, Japan, Russia, the UK, and the U.S., plus the EU.

${ }^{8}$ Metadata is information about the data, including its format and provenance, i.e. how it was acquired, the extent of quality control and curation, etc.
} 


\subsubsection{Information}

As Chap. 1 brings out, cases abound in which satellite Earth observations help to identify and monitor environmental problems or assess progress toward solving them. In some of these cases, institutional mechanisms exist and allow interaction among providers and users but too often such interaction occurs at a stage when decisions regarding instrumentation and data processing capacities have already been made.

Especially in the climate and biodiversity areas, environmental users of satellite Earth observation data have made progress in coordinating their interactions with data providers. An important example features the 50 Essential Climate Variables (ECVs), each with its desired requirements for accuracy and spatial and temporal resolution, defined by the Global Climate Observing System (GCOS) in close interaction with the Intergovernmental Panel on Climate Change (IPCC) and UN Framework Convention on Climate Change (UNFCCC) (Bojinski et al. 2014). These ECVs are also applicable to a range of adjacent environmental issues, such as air quality monitoring and forecasting as well as water resource management (Tan 2014). A corresponding set of Essential Biodiversity Variables (EBVs) are being developed under the GEO Biodiversity Observation Network (BON), in response to the Aichi Targets for 2020 defined under the UN Convention on Biological Diversity (UNCBD) (Pereira et al. 2013). The BON initiative links leading space agencies with scientific and governmental actors at national and international levels, including the Intergovernmental Science-Policy Platform on Biodiversity and Ecosystem Services (IPBES). Among its ongoing projects is to develop a "BON in a Box" regionally adaptable toolkit aiming to harmonize local, national, or regional biodiversity monitoring initiatives. ${ }^{9}$ These and other initiatives aim at making satellite Earth observation data relevant to a broader set of environmental monitoring efforts than hitherto.

Among the strengths of the essential variable approach is to provide focal points for Earth observation data providers when planning missions and instrumentation payloads. In many cases, benefitting fully from satellite capabilities will require recurrent interaction among users and those responsible for mission planning and subsequent data processing. Such recurrent interaction will be particularly important for the ongoing efforts to develop essential variables for monitoring and assessing marine ecosystems, in part because biological and ecological characteristics interact in ways that are often complex, poorly understood and, especially relevant to our discussion, varying in importance seasonally and over time (Hayes et al. 2015). To illustrate, high up on the list of candidate essential marine ecosystem variables is satellite-observed, color-variant chlorophyll concentration, indicative of phytoplankton density and primary production more generally. However, the algorithm used to convert ocean color into estimates of standing

\footnotetext{
${ }^{9}$ On the GEO BON initiative, see https://www.earthobservations.org/activity.php?id=35 (accessed 8 August 2016).
} 
stocks of phytoplankton and primary production must take into account time and space variant factors, such as relative abundance of species, the layering of chlorophyll in the water column, and in some interesting locations, the standing stocks of algae in and under the ice (Constable et al. 2016). The intensity and recurrence of provider-user interaction needed to optimize the role of satellite data in an overall monitoring effort, taking into account the relative costs of alternative acquisition methods, is likely to vary considerably among environmental regimes.

While the most well-known examples of satellite observations supporting assessment of progress in environmental governance are found in the ozone and climate areas (see Chap. 1), some innovative providers are exploring new or more extensive applications of existing data and observing capabilities. Consider the example of the Global Mangrove Watch, developed by the Japan Aerospace Exploration Agency (JAXA) in partnership with, among others, the global NGO Wetlands International and offered as a tool for the Global Wetland Observing System under the Ramsar Convention (Rosenqvist et al. 2014). Trends in mangrove cover can be highly relevant also for assessing progress or setbacks under UN conventions on climate change (UNFCCC), biodiversity (UNCBD) and conservation of migratory species of wild animals (Convention on the Conservation of Migratory Species of Wild Animals, CMS) (Lucas et al. 2014). The JAXA initiative exploits the longevity of global-scale remote sensing at frequencies conducive to mangrove observation in combination with rapidly advancing data processing capacity. Such conduciveness for particular environmental applications would be stronger and more effective if a broader range of actual and potential users, spanning the functional ambits of several environmental regimes, were to be consulted at the planning stage of satellite Earth observation missions.

\subsubsection{Assistance}

Goals pursued under some international environmental agreements fuse with broader societal-security concerns, not least those aiming to prevent and respond effectively to environmental disasters such as floods and wildfires. Satellite-derived information can support each stage of the disaster management cycle, including prevention, warning, response, and recovery. Sweta and Bijker (2013) point out that those engaged in the various stages of the disaster management cycle differ widely as to what they perceive as decisive quality characteristics of Earth observation data and in terms of the extent of metadata needed. This situation suggests that new arenas and more inclusive review procedures would help to improve the fitness of the wide range of available Earth observation products to the distinctive needs of diverse users.

Considering that the meteorological community has been prominent among the non-military users of Earth observation data ever since the dawn of the satellite era (Edwards 2006), it is understandable that flood management is an area with relatively firm institutional links along the provider-user chain, especially with respect 
to early warning. Geostationary satellites hovering over fixed positions allow meteorological agencies to issue forecasts of where and when thunderstorms are about to hit and where the likelihood of flash floods is particularly high (Tan 2014). WMO has played an active role in integrating satellite and otherwise-obtained data for this purpose, including through its Flood Forecasting Initiative (FFI). This initiative, operational since 2003, builds capacity among meteorological and hydrological agencies in developing countries to compile and disseminate the relevant information in flood-critical situations to those responsible for civil protection and response (Sene 2008).

Important as it is to empower meteorological and hydrological agencies by means of satellite Earth observation data, the overall flood management capacities of exposed regions are likely to benefit even more if patterns of involvement are expanded further. As reflected in a series of soft-law instruments under the 1992 UN Economic Commission for Europe (UNECE) Water Convention (the environmental framework agreement with the longest record of flood-risk responsibility) and in its global counterpart the 1997 UN Watercourses Convention, modern flood protection strategies give pride of place to the water retention capacities of nature itself, including the networks of small waterways, wetlands, soils, and grasslands throughout a river basin (UNECE, 2009). ${ }^{10}$ This environmental dimension of flood protection means that flood management must be an integral part of general river basin management plans often developed by international environmental bodies established by riparian states. While WMO is sensitive to this need for integrated flood management, as evident in the Associated Programme on Flood Management (APFM) initiated jointly with the Global Water Partnership (GWP), ${ }^{11}$ those responsible for such larger river basin management plans are likely to have Earth observation data needs distinctive from those of meteorologists and hydrologists.

Wildfire prevention and response is another area where satellite Earth observation data are key and where institutionalized provider-user interaction may help to tailor relevant information products to the needs of environmental managers. The environmental and societal challenges posed by wildfires are enormous. In the World Bank's disaster management portfolio, only projects addressing floods and droughts have been more numerous (IEG 2006). One means for linking providers and users in this field is the Fire Program of the Global Observation for Forest Cover and Land Dynamics (GOFC-GOLD) effort, an international partnership including the Committee on Earth Observation Satellites (CEOS; a coordinating body for space agencies) as well as research communities, NGOs, and subsidiary bodies of the UNFCCC and UN Convention to Combat Desertification (UNCCD)

\footnotetext{
${ }^{10}$ See Model Provisions on Transboundary Flood Management, especially Provision 4, reproduced in ECE (2009, Annex I).

${ }^{11}$ More information at the program's website, http://www.apfm.info/ (accessed 16 August 2016).
} 
(Calle and Casanova 2008). Among the projects contributing to this program is the Fire Information for Resource Management System (FIRMS), a set of applications providing access to near real-time web-based fire maps and associated data sets without exceeding the limited download capacities of many developing countries (Davies et al. 2009). While close interaction with focus groups of Earth observation data users in Central America, Africa, and Asia was important to the design of these applications, the project is provider-initiated and interaction with users have revolved around the processing and dissemination of satellite data, not data acquisition.

Efforts to prevent and respond to disasters such as floods and wildfires are increasingly integrated within larger environmental management plans, thus involving national and international environmental agencies with Earth observation data needs that may exceed or differ from those defined by civil protection agencies. Such diversity should be reflected in increasingly institutionalized provider-user interactions that aim to enhance the role of satellite data in supporting disaster management.

\subsubsection{Compliance}

Involvement of existing and potential environmental management users is no less important when designing new Earth observation products for the third major function of satellite data in environmental problem solving, improving adherence to international commitments. As noted in Chap. 1, many states have used satellite data as part of their national inventory reporting under the Kyoto Protocol, especially with respect to emissions and removals associated with land use and land cover changes (e.g., Reddy et al. 2015). They will continue to do so for pledges under the 2015 Paris Agreement. In other sectors such as fisheries management, satellite observations can also be crucial to verification and review activities, those parts of a regime's compliance system that evaluate the reliability of national or target group reports by providing independent information suitable for cross-checking.

Satellite-based tracking of individual fishing vessels as part of systems for compliance monitoring is a well-established practice in many regional fisheries management regimes. So far, however, these vessel monitoring systems have required specially devised on-board transponders typically linked to flag-state enforcement agencies and have therefore been relevant only for vessels registered with a regime member. The Global Fishing Watch initiative by Google (a relative newcomer among Earth observation data providers) in partnership with certain NGOs interested in Illegal, Unreported, and Unregulated (IUU) fishing, seeks to overcome that limitation by using instead the AIS signals that IMO has mandated 
for certain vessel types under its Safety of Life at Sea Convention (Ouellette and Getinet 2016; see also Chap. 1). ${ }^{12}$

In order to function as intended, however, the Global Fishing Watch initiative needs complementary action under global and regional institutions responsible for maritime safety or resource management (McCauley 2016), action that is not necessarily forthcoming. IMO mandates AIS transponders only for vessels larger than 300 gross tons and engaged in international voyages, meaning that application to most fishing vessels is discretionary for the flag states. Unfortunately, IUU fishers are frequently registered by flags-of-convenience states unlikely to prioritize compliance. A 2015 submission by two environmental NGOs encouraging a Joint FAO/IMO Ad Hoc Working Group on IUU Fishing to advocate stricter AIS regulations met with a lukewarm response (FAO 2015). Among the counter arguments is the expectation that use of the AIS system for compliance purposes might encourage tampering or even disabling the transponders, undermining the safety-at-sea objectives that motivated the creation of the system. Some states and regional organizations have nevertheless mandated AIS signals for large parts of their fishing fleets. Even if regulatory developments are slow at the global level, this satellite-supported tool may become important in combatting IUU fishing.

As with the information and assistance roles, designing steadily more effective Earth observation products for compliance purposes frequently requires coordination among data providers and users with sufficiently high stakes in the outcome to mobilize political energy for creating an effective institutional environment.

\subsection{Organizational Issues}

It is neither practical nor efficient for most regimes established to solve specific environmental problems to operate their own Earth observation systems. This is true even for those dealing with global or widespread issues like the depletion of stratospheric ozone or the destruction of tropical forests. What we can expect in this realm is the emergence of a complex of institutions involving providers of Earth observation data that have specialized in the development of capabilities involving the acquisition and management of data together with a range of potential users that require data for different purposes. Those users may want to develop means of integrating Earth observation data with other types of data to maximize their effectiveness in solving the problems that fall within their remit. As a result, it is important to address a series of issues that center on developing productive relations between providers and users of Earth observation data. Partly, this is a matter of achieving a good match between the capabilities of the providers and the needs of the users to maximize success in solving specific problems. In part, however, it is a

\footnotetext{
${ }^{12}$ For details of this Global Fishing Watch initiative, see http://globalfishingwatch.org/ (accessed 30 August 2016).
} 
matter of developing rules governing the provider-user interface to ensure that this relationship conforms to broader societal preferences. Should Earth observation data providers make data available free of charge, for example, or is it legitimate for them to charge for their services? If charges are involved, should users of Earth observation data be allowed to shop among providers in order to obtain the most favorable deals for their purposes?

\subsubsection{An Earth Observation Environmental Data Forum}

So long as Earth observation data providers and users responsible for implementing environmental regimes operate independently, it is unlikely that the data from providers will dovetail well with user needs. Left to their own devices, providers will design payloads that focus on the latest technologies and cutting-edge capabilities regarding the acquisition of data. For their part, users are likely to formulate their requests for data with little attention to the practical limits of what the providers can supply given realistic cost constraints. What is needed in this regard is a conscious effort to find ways to bring together the providers and the users not only at the stage of distributing available data to individual users but also at the stage of planning regarding the number and types of satellites to launch and the instrumentation packages loaded on individual satellites. In effect, there is a need for an end-to-end relationship in which providers and users engage in cooperative efforts all the way from designing missions to evaluating the results and planning for improved missions at a later stage.

What is the best way to engage in this sort of matchmaking? Assuming that the community of providers and the community of users remain separate groups with their own goals and objectives, there are several strategies that may prove helpful in this regard. One strategy is to match specific providers (e.g., ESA or JAXA) with particular users (e.g., those responsible for administering the ozone regime, the climate regime, or the biodiversity regime). This would allow for intensive engagement focused on the data needs of those seeking to solve specific environmental problems. Another strategy is to focus on the functions we reviewed above (i.e., inform, assist, comply) and to match the capabilities of EO data providers with the sorts of data needed to handle each of these functions.

While these strategies may make sense under some circumstances, they have obvious drawbacks as general approaches to matchmaking between providers and users of Earth observation data. There is considerable overlap among environmental regimes in their needs for data, so it makes sense to look for synergies in responding to these needs and to encourage cross-regime communication designed to make use of Earth observation data in the most efficient way. Similarly, many individual regimes involve needs for data covering the full range of functions we have identified. In such cases, it makes sense to look for ways to coordinate efforts to 
provide the different types of data needed by regime administrators in an efficient manner.

One interesting response to these concerns would be to develop an informal but nevertheless well-defined and functionally broad forum in which providers and users of Earth observation data relevant to solving environmental problems could interact with each other to discuss issues involving the match or fit between the capabilities of providers and the needs of users. Such a forum would not be a substitute for the development of contractual agreements between specific providers and users covering their terms of engagement (see Sect. 16.5.2). Rather, the Earth observation environmental data forum would provide a more general setting for discussion of emerging capabilities in this field and the evolution of environmental regimes creating new uses for Earth observation data. GEO might play a constructive role in orchestrating the participation of providers in such a forum. An Earth observation environmental data forum would follow up on the call by the GEO Ministerial meeting in 2015 to "strengthen its focus on users and stakeholders and in particular develop new approaches to effectively engage with ... Multilateral Environmental Agreements" (GEO 2015b).

There is no counterpart to GEO on the environmental user side. However, the UN Environment Programme (UNEP), the World Bank, and the Global Environment Facility (GEF) are involved in the implementation and funding of many of the major international environmental regimes; UNEP and the World Bank are also GEO partners. Building on the experiences from endeavors that involve individual international environmental regimes, such as the definition of ECVs, a broader Earth observation environmental data forum could facilitate similar processes among wider sets of users, linking them to relevant provider expertise on advances in technological capabilities and on remaining cost constraints. The scope of participation by those responsible for operating environmental regimes could vary depending on the substantive focus of each forum meeting, which may be defined in terms of issue area (e.g., forestry, fisheries, biodiversity) or function, or any combination of these.

There is no need to formalize relations among these entities regarding the creation and operation of an Earth observation environmental data forum. But there is an opportunity for the progressive development of social practices in this realm. Deeper involvement on the part of major international funding agencies such as GEF and the World Bank would allow such a forum to benefit from the particular experience and expertise those agencies have in evaluating societal benefits across environmental projects and issue areas. They could also provide financial muscle to fund specific Earth observation activities tailored to their project portfolios - the World Bank is a major user of Earth observation data in support of its investment decisions and project implementation (Royal Society 2015). It might well be appropriate for the GEF to provide the relatively modest funding needed to support periodic meetings of an Earth observation environmental data forum bringing together leading providers and users. 


\subsubsection{Terms of Engagement}

There remains the issue of the contractual arrangements covering relations between providers and users regarding the use of specific data applied to particular environmental problems. Many of those who have thought about the uses of Earth observation data believe that publicly funded agencies (e.g., ESA, JAXA, NASA) should be responsible for the collection of relevant data and that the data they obtain should be made available for environmental problem solving on a free-and-open basis. On the other hand, as we have noted, private companies are entering the ranks of Earth observation data providers; they advertise their services as efficient sources of data needed to handle a variety of functions. These observations raise a number of classic issues regarding the relative merits of public and private provision of various services. Without going into detail regarding these underlying issues, we can identify and comment on several concrete matters relating to the terms of engagement between Earth observation data providers and users in need of particular types of data to address the environmental problems they seek to solve.

Today, many countries (including developing countries like China and India) and a growing number of private corporations operate satellites and use them to collect various types of data on a regular basis. This suggests that users endeavoring to solve specific environmental problems may be tempted to shop around, searching for different types of data to meet their needs from a variety of providers. Nonetheless, both providers and users may find that they have significant incentives to form clear-cut (though not necessarily exclusive) and lasting relationships covering the terms of engagement between them regarding the provision and use of Earth observation data.

For one thing, individual users may wish to have input at the design stage, participating in decisions relating to the instrument packages loaded on specific satellites, the orbits of satellites, or arrangements involving the coordination of two or more satellites to ensure needed coverage, in return for making long-term commitments to using the services of a particular provider. If the problem is simply a matter of monitoring rates of loss of tropical forests or the magnitude of marine dead zones, it may be sufficient to work with low-resolution images that are collected on a weekly or even monthly basis. When the problem is a matter of providing early warning regarding tidal waves likely to hit exposed coasts or forecasting where and when a hurricane will make landfall, there is a need for higher temporal resolution data that can be collected and disseminated rapidly. While providers have coordinating mechanisms of their own (e.g., CEOS and GEO) and users tend to be grouped into distinct regimes dealing with separate issues (e.g., stratospheric ozone depletion, marine pollution, deforestation), there may be good reasons to make a concerted effort to bridge this gap when it comes to addressing specific environmental problems. One way to do this is to move toward the formation of lasting contractual relationships organized around regime complexes encompassing all those players endeavoring to solve more or less well-defined environmental problems. 
Users will often want to merge data obtained from a variety of sources, including observations from aircraft, in situ monitoring devices, and mobile sources as well as satellite Earth observation data. In such cases, they will have an incentive to work with multiple providers to develop programmatic arrangements that maximize their ability to carry out monitoring, reporting, and verification functions effectively. Unlike consumers whose engagement with providers is likely to end once they have completed the purchase of a specific product, relationships between providers of data and users dealing with environmental problems will normally be complex and ongoing. This suggests that both sides will find it beneficial to spell out terms of engagement in relatively explicit contractual agreements. There may even be reasons to develop mutually agreed procedures to provide authoritative interpretations of the terms of resultant contracts when the parties disagree about their application to specific situations.

When public agencies are in need of services, ranging from the construction of infrastructure to the provision of security services at public facilities, it is normal to issue requests for proposals and to establish some procedure both to evaluate the merits of the proposals received and to make decisions regarding preferred proposals. The evaluation may include a variety of considerations relating to the track record of the providers and the quality of the services to be provided as well as the proposed budget. For various reasons, this model may not be applicable to the relationships between Earth observation providers and users we are considering in this analysis. Among other things, the providers themselves may be public agencies and there may be questions regarding the extent to which it is appropriate to charge for providing the relevant data. Still, there is merit in thinking in contractual terms about the provision of Earth observation data to address specific environmental problems, especially in cases where the options include turning to private enterprises as sources of supply. Among other things, an approach of this sort can produce well-defined and stable expectations on the part of all participants, a matter of particular importance in relationships that are expected to last indefinitely and to adapt successfully to changing circumstances.

With regard to the specific question of payment for the provision of Earth observation data, there is no simple answer. The current trend in which space agencies increasingly provide Earth observation data on an open-access basis is appealing not only for ideological reasons but also because environmental regimes are seldom well-endowed with funds that would be needed to purchase data. Still, it would be a mistake to jump to the conclusion that free-and-open access is the preferred policy under all conditions. Supporting the growth of national space industries and associated technology development is a major priority for governments active in this sector (OECD 2014). Among ESA member states, for instance, strengthening industrial competitiveness is the most frequently cited motivation for space activities (Adriaensen et al. 2015). It is not surprising, therefore, that policies of open access to data free of charge are questioned and sometimes opposed by companies that specialize in the provision of Earth observation products similar to 
those increasingly available at no cost. CNES, for example, specifically confined its zero-cost policy to older and medium resolution Earth observation data so as not to undercut markets exploited by its SPOT partner Airbus Defence and Space (Selding 2014). The European Commission has reportedly promised to adjust its Copernicus Data Policy should it jeopardize the viability of European private satellite operators. $^{13}$

Moreover, users often need to order specialized data to address the problems they are seeking to solve. In some cases, private providers may be more responsive to these needs and more efficient in minimizing the costs involved, as illustrated in the role of commercial actors in developing networked systems of smaller and smaller satellites (OECD 2014). More generally, we should not exclude the possibility that private providers have more compelling incentives to develop new or more cost-efficient observing systems and finding ingenious ways to configure them to meet the needs of certain users.

None of this is meant to undermine the premise that open-access data supplied by national space agencies will prove to be the best option under a variety of conditions. But it is clear that we should not simply assume that this option constitutes the preferred strategy in all cases. In efforts to come to terms with the provider-user interface on a case-by-case basis, the issue of financial arrangements must be tackled head on with the objective of arriving at mutually satisfactory arrangements.

\subsection{Impacts on Earth Observation Sustainability}

Placing environmental institutions more centrally in the larger Earth observation environmental regime complex promises to enhance the role of satellite data in environmental problem solving. But it also involves costs for Earth observation data providers that, for long-term sustainability, must somehow be balanced by substantive provider benefits. Among the costs are not only the time and energy that providers must invest in various processes for identifying the environmental needs that match existing or future acquisition and processing capacities but also the opportunity costs of instrumentation packaging specially tailored for environmental problem solving. To illustrate this observation, we address three impacts of firmer connections among Earth observation data providers and environmental agencies, revolving around economic viability, environmental sustainability, and certain normative or ethical concerns that loom steadily larger as satellite systems become more sophisticated.

\footnotetext{
${ }^{13}$ See Selding (2014): "the Commission may reassess the sensitivity of specific Copernicus data on its own initiative or at the request of a member state"; see also EU (2013), Art. 15.
} 


\subsubsection{Economic Viability}

The end of the Cold War made it less compelling for governments to allocate resources to space activities for security reasons, as did the rising preparedness of private actors to develop space capacities independent of taxpayer support. These developments have raised questions about the stability of public funding for the major space agencies. In the case of NASA, the political support for its budget has been perceived, in the words of one observer, as "a mile wide but an inch deep" (Handberg 2003; cited in Cobb and WNW 2011). Obtaining the necessary long-term funding for Earth observation activities is seen as particularly challenging since they do not typically provide spectacular "space events", like landings on the moon or explorations of Mars, that have fuelled popular interest in and support for space activities (Morel 2013). Some leading spacefaring nations have seen considerable variation in the public support for spending on space. Surveys indicate that the share of the US public that considers government spending on space activities as excessive rose from about a third in 1988 to around half in the mid-1990s, then leveled off to around 40\% (Cobb and WNW 2011).

Despite these worries over the economic viability of space activities, governmental space budgets supporting civilian uses have proven stable among the OECD countries, even during the financial crisis of 2008-2009, whereas emerging economies like China, India, and Brazil have increased their space budgets considerably (OECD 2014). As highlighted by Gaubert (2002), governmental preparedness to pay for space activities derives in part from interest among space-capable states to retain or improve their competitiveness in a technology-intensive and growth-driving sector. A recent review of European national space strategies indicates that only security and transportation loom larger than environment and resource management among priority areas seen as benefitting from engagement in space activities (Adriaensen et al. 2015). New initiatives that broaden and enhance the use of satellite data for environmental problem solving are likely to stabilize and reinforce the perception that public spending on space activities is money well spent, adding to the social capital of those engaged in the space sector.

Indirectly, therefore, enhanced contributions to environmental problem solving are likely to contribute to the financial viability of space-based Earth observation activities, even if the environmental regimes that stand to benefit are not charged directly for these services. Economic benefits for providers can also be more direct, especially when intensive or recurrent provider-user interaction promises to generate specially tailored Earth observation products, enabling more efficient or cost-effective operation of certain governance tasks, such as problem monitoring or compliance control. In such situations, international environmental bodies may be motivated to contribute financially to realize the product, either directly through their own budgets or (perhaps more frequently) through related environmental funding agencies such as the GEF or one of the many funds for climate action. As noted above, active involvement of the GEF and the World Bank in a broader Earth 
observation environmental data forum would likely promote the ability of international environmental regimes to trigger financial muscle in support of satellite-based Earth observation activities.

\subsubsection{Environmental Sustainability}

A more prominent role for satellite Earth observation in environmental problem solving would strengthen one strand of a broader effort to improve the environmental sustainability of space activities. The other strand of that effort has revolved around a series of congestion problems in outer space, notably the scarcity of orbits appropriate for geosynchronous or sun synchronous observation, the rising challenge of frequency interference, and the risks space debris poses to safe spacecraft operation, including those resulting from collisions or intentional destruction of satellites (Williamson 2012). ${ }^{14}$ The rising prominence of outer space sustainability is evident in the adoption of the 2007 Space Debris Mitigation Guidelines by the UN Committee on the Peaceful Uses of Outer Space (COPUOS) and in that Committee's decision to place outer space sustainability on its agenda from 2010 onwards, having tasked a Working Group on Space Sustainability with developing specific inputs suitable for best-practice guidelines concerning debris, the safety of space operations, and management of the radio-electric spectrum (Brachet 2012).

Like any sector that generates obvious societal benefits but also threatens certain environmental qualities or exploits finite resources, those engaging in private or public space activities must demonstrate awareness of the environmental problems they generate and dynamism in efforts to mitigate them. Developing and exploiting positive externalities by using facilities in space to solve sustainability problems on Earth fits well with the sector's growing preparedness to place negative externalities in outer space such as debris and congestion on the international political agenda.

\subsubsection{Normative or Ethical Concerns}

Even if the terms of engagement governing interactions between providers and users of Earth observation environmental data are well-defined and widely understood, there are some important normative issues that arise in this realm and that are destined to take on greater prominence as satellites become more sophisticated and, in the process, capable of providing a growing array of services of interest to those endeavoring to solve environmental problems. For the most part, these are specific

\footnotetext{
${ }^{14}$ In 2007 China deliberately destroyed one of its own inoperative meteorological satellites using a ground-based missile, generating more than 3000 long-lived fragments; half of that number of debris fragments were produced by an accidental collision of two US-operated satellites (Brachet 2012).
} 
versions of issues arising in a wide range of settings as the power of information systems increases. Should there be rules regarding rights to privacy on the part of those whose activities are being monitored (e.g., emitters of greenhouse gases) or whose activities play a role in causing environmental problems of public concern (e.g., users of chemical fertilizers and pesticides)? Is it important to be concerned about the potential for corrupt or unethical behavior on the part of either providers or users of Earth observation data? Are there or should there be safeguards regarding the handling of such data in the event that anti-democratic forces achieve growing influence or political turmoil ensues? None of these concerns is unique to the realm of Earth observation environmental data; they arise in many settings. Experience with the integrity of information systems in other settings can be applied to the development of an Earth observation environmental regime complex. But it will be important for both providers and users to be conscious of these concerns and to adapt general responses to the specific circumstances arising in conjunction with Earth observation environmental data.

\subsection{Conclusion}

We have approached the development of an Earth observation environmental regime complex largely as a matter of building productive relationships between two distinct communities to enhance capacity to provide information, assist in preventing or mitigating disasters, and improve compliance regarding a range of environmental problems. We expect that the provider community, including private companies as well as public space agencies, and the user community, including those responsible for building and implementing a wide range of environmental regimes, will remain distinct. But it will be important to devise and strengthen terms of engagement that allow the two communities to develop end-to-end relationships starting with the design of space missions and payloads and carrying through to the assessment of performance in addressing a variety of tasks and improving the design of future missions. In our judgment, there is room not only for minimizing tensions in the relationships between these communities but also to achieve a higher level of synergy that improves the performance of environmental regimes and solidifies support for space agencies. Making use of our general knowledge of regime interplay, we have identified the principal elements of the terms of engagement between the two communities and discussed ways to develop these terms in a manner that benefits both communities going forward. One practical step that may prove helpful in this context is to launch an Earth observation environmental data forum with a mandate to foster enhanced coordination between the two communities. 


\section{References}

Adriaensen $\mathrm{M}$ et al (2015) Priorities in national space strategies and governance of the member states of the European Space Agency. Acta Astronaut 117:356-367

Bailey $\mathrm{G}$ et al (2001) International collaboration: the cornerstone of satellite land remote sensing in the 21st century. Space Policy 17:161-169

Belward A, Skøien JO (2015) Who launched what, when and why; trends in global land-cover observation capacity from civilian Earth observation satellites. ISPRS J Photogrammetry Remote Sens 103:115-128

Biermann F et al (2009) The fragmentation of global governance architectures: a framework for analysis. Glob Environ Politics 9:14-40

Bojinski S et al (2014) The concept of essential climate variables in support of climate research, applications, and policy. Bull Am Meteorol Soc 95:1431-1443

Brachet G (2012) The origins of the "Long-term Sustainability of Outer Space Activities" initiative at UN COPUOS. Space Policy 28:161-165

Calle A, Casanova JL (2008) Forest fires and remote sensing. In: Coskun HG et al (eds) Integration of information for environmental security. Springer, Dordrecht

Cobb, WNW (2011) Who's supporting space activities? An 'issue public' for US space policy. Space Policy 27:234-239

Constable AJ et al (2016) Developing priority variables ("ecosystem Essential Ocean Variables"eEOVs) for observing dynamics and change in Southern Ocean ecosystems. J Marine Sys 161:26-41

Davies DK et al (2009) Fire Information for Resource Management System: archiving and distributing MODIS active fire data. IEEE Trans Geosci Remote Sens 47(1):72-79

Dillow RK (2012) World Weather Watch. In: Encyclopedia of Global Warming \& Climate Change. SAGE Publications, Thousand Oaks

Edwards PN (2006) Meteorology as infrastructural globalism. Osiris 21:229-250

European Commission (2013) Commission Delegated Regulation (EU) No 1159/2013 supplementing Regulation (EU) No 911/2010 of the European Parliament and of the Council on the European Earth monitoring programme (GMES) by establishing registration and licensing conditions for GMES users and defining criteria for restricting access to GMES dedicated data and GMES service information. Official Journal of the European Union L 309/1

European Space Agency (2012) ESA data policy for ERS, Envisat and earth explorer missions. https://earth.esa.int/c/document_library/get_file?folderId=296006\&name=DLFE-3602.pdf. Accessed 6 Sep 2016

FAO, Food and Agriculture Organization (2015) Report of the third session of the Joint FAO/IMO ad hoc Working Group on Illegal, Unreported and Unregulated (IUU) Fishing and Related Matters. http://www.fao.org/3/a-i5736e.pdf. Accessed 8 Dec 2016

Gaubert A (2002) Public funding of space activities: a case of semantics and misdirection. Space Policy 18:287-292

GEO, Group on Earth Observations (2015a) GEOSS data management principles. https://www. earthobservations.org/documents/dswg/201504_data_management_principles_long_final.pdf. Accessed 6 Sep 2016

GEO, Group on Earth Observations (2015b) Mexico City Declaration. http://www. earthobservations.org/documents/ministerial/mexico_city/MS3_Mexico_City_Declaration.pdf. Accessed 3 Aug 2016

Handberg R (2003) Reinventing NASA: human spaceflight, bureaucracy, and politics. Praeger, Headport

Harris R, Baumann I (2015) Open data policies and satellite Earth observation. Space Policy 32:44-53

Harris R, Browning R (2003) Global monitoring for environment and security: data policy considerations. Space Policy 19:265-276 
Hayes KR et al (2015) Identifying indicators and essential variables for marine ecosystems. Ecol Ind 57:409-419

IEG, World Bank Independent Evaluation Group (2006) Hazards of nature, risks to development: an IEG evaluation of World Bank assistance for natural disasters. World Bank, Washington, D.C., USA

Kuriyama I (2005) Supporting multilateral environmental agreement with satellite Earth observation. Space Policy 21:151-160

Lucas R et al (2014) Contribution of L-band SAR to systematic global mangrove monitoring. Mar Freshw Res 65:589-603

McCauley DJ (2016) Ending hide and seek at sea. Science 351:1148-1150

Morel P (2013) Advancing Earth observation from space: a global challenge. Space Policy 29:175-180

Oberthür S, Gehring T (2006) Institutional interaction in global environmental governance: synergy and conflict among international and EU policies. MIT Press, Cambridge

Oberthür S, Stokke OS (2011) Managing institutional complexity: regime interplay and global environmental change. MIT Press, Cambridge, Massachusetts, USA

OECD (2012) Meeting global challenges through better governance: international co-operation in science, technology and innovation. OECD Publishing, Paris

OECD (2014) The space economy at a glance. OECD Publishing, Paris

Orsini A et al (2013) Regime complexes: a buzz, a boom, or a boost for global governance? Glob Gov 19:27-39

Ouellette W, Getinet W (2016) Remote sensing for marine spatial planning and integrated coastal areas management: achievements, challenges, opportunities and future prospects. Remote Sens Appl Soc Environ 4:138-157

Pereira H et al (2013) Essential biodiversity variables. Science 339:277-278

Raustiala K, Victor DG (2004) The regime complex for plant genetic resources. Int Organ 58(2):277-309

Rosenqvist A et al (2014) Global Mangrove Watch (GMW) - project update and progress in its implementation as a pilot to the Ramsar GWOS. In: Scientific and Technical Review Panel of the Ramsar Convention on Wetlands 18

Reddy S et al (2015) Enhancing the national carbon accounting and reporting capability using remote sensing data. In: Applications of satellite Earth observations: serving society, science, and industry. http://ceos.org/document_management/Publications/Data_Applications_Report/ DAR_Summary-Brochure_Digital-Version_Dec2015.pdf. Accessed 8 Dec 2016

Royal Society (2015) Observing the Earth — expert views on environmental observation of the UK. R Soc, London

Sawyer G, de Vries M (2012) About GMES and data: geese and golden eggs - a study on the economic benefits of a free and open data policy for GMES Sentinels data. European Association of Remote Sensing Companies, Brussels

Schwach V (2000) Havet, fisken, og vitenskapen. Fra fiskeriundersøkelser til Havforskningsinstitutt, Bergen

Selding PB (2014) France to make older Spot images available to researchers for free. http://spacenews. com/39234france-to-make-older-spot-images-available-to-researchers-for-free/. Accessed 6 Sep 2016

Sene K (2008) Flood warning, forecasting and emergency response. Springer Science + Business Media, New York

Smith LJ, Doldirina C (2008) Remote sensing: a case for moving space data towards the public good. Space Policy 24:22-32

Stokke OS (2014) Actor configurations and compliance tasks in international environmental governance. In: Kanie $\mathrm{N}$ et al (eds) Improving global environmental governance. Routledge, New York

Stokke OS (2015) Fisheries and whaling. In: Pattberg PH, Zelli F (eds) Encyclopedia of global environmental governance and politics. Edward Elgar, Cheltenham 
Stokke OS, Oberthür S (2011) Introduction: institutional interaction in global environmental change. In: Oberthür S, Stokke OS (eds) Managing institutional complexity: regime interplay and global environmental change. MIT Press, Cambridge, Massachusetts, USA

Sweta LO, Bijker W (2013) Methodology for assessing the usability of Earth observation-based data for disaster management. Nat Hazards 65:167-199

Tahvonen K (2010) Monitoring oil pollution from ships: experiences from the Northern Baltic Basin. In: Vidas D (ed) Law, technology and science for oceans in globalization: IUU fishing, oil pollution, bioprospecting, outer continental shelf. Martinus Nijhoff, Leiden

Tan SY (2014) Meteorological satellite systems. Springer, New York

UNECE, United Nations Economic Commission for Europe (2009) Transboundary flood risk management: experiences from the UNECE region. United Nations, New York

Viikari L (2007) The environmental element in space law: assessing the present and charting the future. Martinus Nijhoff, Leiden

Weeden BC, Chow T (2012) Taking a common-pool resources approach to space sustainability: a framework and potential policies. Space Policy 28:166-172

Williamson RA (2012) Assuring the sustainability of space activities. Space Policy 28:154-160

Withee GW et al (2004) Progress in multilateral Earth observation cooperation: CEOS, IGOS and the ad hoc Group on Earth Observations. Space Policy 20:37-43

Young OR (1996) Institutional linkages in international society: polar perspectives. Glob Gov 2 (1): $1-23$

Young OR (2002) The institutional dimensions of environmental change: fit, interplay, and scale. MIT Press, Cambridge

\section{Author Biographies}

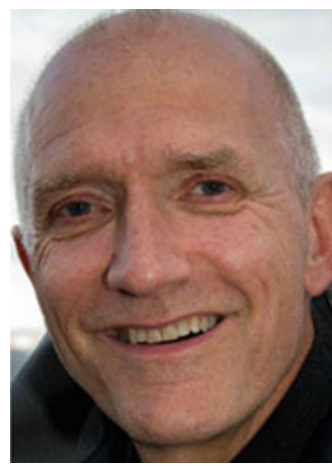

Olav Schram Stokke is a professor of political science at the University of Oslo, the director of the university's crossdisciplinary bachelor's program on international relations, and a research professor at the Fridtjof Nansen Institute (FNI), where he also served as research director for many years. Previous affiliations include the Centre for Advanced Study (CAS) at the Norwegian Academy of Science and Letters and the International Institute for Applied Systems Analysis (IIASA). His area of expertise is international relations with special emphasis on institutional analysis, resource and environmental management, and regional cooperation. Among his recent books are Disaggregating International Regimes: A New Approach to Evaluation and Comparison (MIT Press 2012), Managing Institutional Complexity: Regime Interplay and Global Environmental Change (MIT Press 2011), and International Cooperation and Arctic Governance (Routledge 2007/2010, Chinese version by Ocean Press of China 2014). He publishes in leading international journals, including Annals of the American Academy for Political and Social Science, Cooperation and Conflict, Global Environmental Politics, International Environmental Agreements, International Journal of Business Research, Marine Policy, Ocean and Coastal Management, Ocean Development and International Law, and Strategic Analysis. 


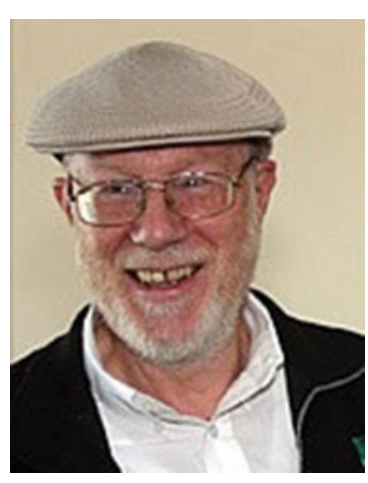

Oran R. Young is a renowned Arctic expert and a world leader in the fields of international governance and environmental institutions. His scientific work encompasses both basic research focusing on collective choice and social institutions, and applied research dealing with issues pertaining to international environmental governance and the Arctic as an international region. Professor Young served for 6 years as vice-president of the International Arctic Science Committee and was the founding chair of the Committee on the Human Dimensions of Global Change within the National Academy of Sciences in the USA. He currently chairs the Scientific Committee of the International Human Dimensions Programme on Global Environmental Change and the Steering Committee of the Arctic Governance Project.

Open Access This chapter is licensed under the terms of the Creative Commons Attribution 4.0 International License (http://creativecommons.org/licenses/by/4.0/), which permits use, sharing, adaptation, distribution and reproduction in any medium or format, as long as you give appropriate credit to the original author(s) and the source, provide a link to the Creative Commons license and indicate if changes were made.

The images or other third party material in this chapter are included in the chapter's Creative Commons license, unless indicated otherwise in a credit line to the material. If material is not included in the chapter's Creative Commons license and your intended use is not permitted by statutory regulation or exceeds the permitted use, you will need to obtain permission directly from the copyright holder.

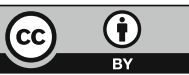

